\title{
Multiplex Quantitative Real-Time PCR of Laser Microdissected Tissue
}

\author{
Patrick H. Rooney
}

\begin{abstract}
Summary
This chapter describes a method for the rapid assessment of gene copy number in laser microdissected material using multiplex real-time polymerase chain reaction (PCR). Here a putative oncogene (ZNF217) was evaluated in a series of colon tumors, but the method is applicable to any locus for which a nucleic acid sequence is available. The preparation, laser microdissection, and optimum storage of snap-frozen tumor material from freshly resected tissue is described. A set of guidelines specific for real-time PCR assays is included to assist with optimum primer and probe design. In this assay multiplex real-time PCR was performed and our experience has demonstrated that a multiplex reaction allows for a more accurate assessment of gene copy number than a "singleplex" assay because it removes the need for an external control.
\end{abstract}

Key Words: Colon cancer; quantitative real-time PCR; ZNF217; gene copy number; laser microdissection; multiplex PCR; ABI7700 sequence detector.

\section{Introduction}

Detection of gene amplification is a recognized process through which oncogenes can be identified. Traditionally, gene copy number has been assessed through labor-intensive methods requiring several micrograms of test DNA, such as Southern blotting (1) and fluorescent in situ hybridization (FISH) (2). With the advent of laser microdissection (3) and quantitative real-time polymerase chain reaction (PCR) $(4)$, the accurate quantification of gene copy in samples containing quantities of DNA several orders of magnitude less than the more traditional techniques has become possible. Nanograms of starting material rather than micrograms allows an investigator more freedom to precisely assess gene copy number in a particular region of tissue they have previ- 

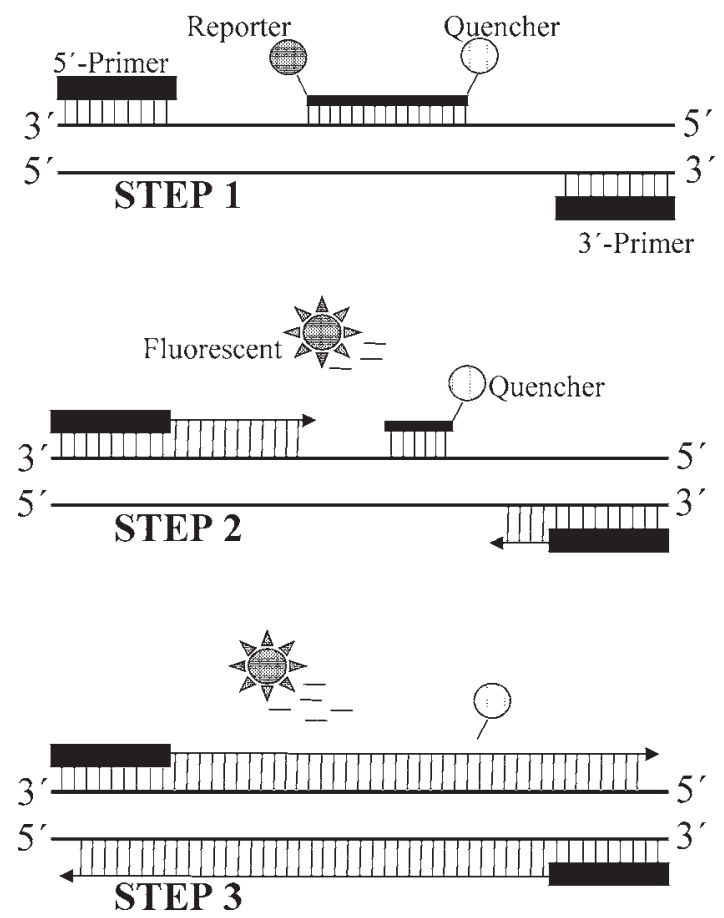

Fig. 1. Real-time PCR. Step 1: A fluorescent reporter and a quencher, are attached to the $5^{\prime}$ and $3^{\prime}$ ends of a probe specific for the locus of interest (when both molecules are attached to the probe, reporter dye emission is quenched). Step 2: During each extension cycle, polymerase cleaves the reporter from the probe. Step 3: The quencher is also released and this allows the reporter to emit fluorescence. The intensity of the fluorescent signal generated is directly proportional to the cleavage of probe, which is directly proportional to the amount of starting template.

ously selected (e.g., tumor). The application of laser microdissection coupled with quantitative real-time PCR removes the need for large quantities of DNA that can often be contaminated with surrounding material. With no dilution of gene amplification from surrounding diploid tissue, a more accurate measure of gene amplification can be obtained.

Quantitative real-time PCR determines the copy number of a specific gene by measuring the accumulation of this candidate at every point in a polymerase chain reaction $(5,6)$. This is achieved with conventional forward and reverse primers and by a fluorogenic probe (7) specific for the sequence of interest that is incorporated into the PCR product by a polymerase enzyme containing 5 ' nuclease activity (Fig. 1). Detection of the fluorescent signal from the resulting PCR product allows quantification of the starting template. The fewer 


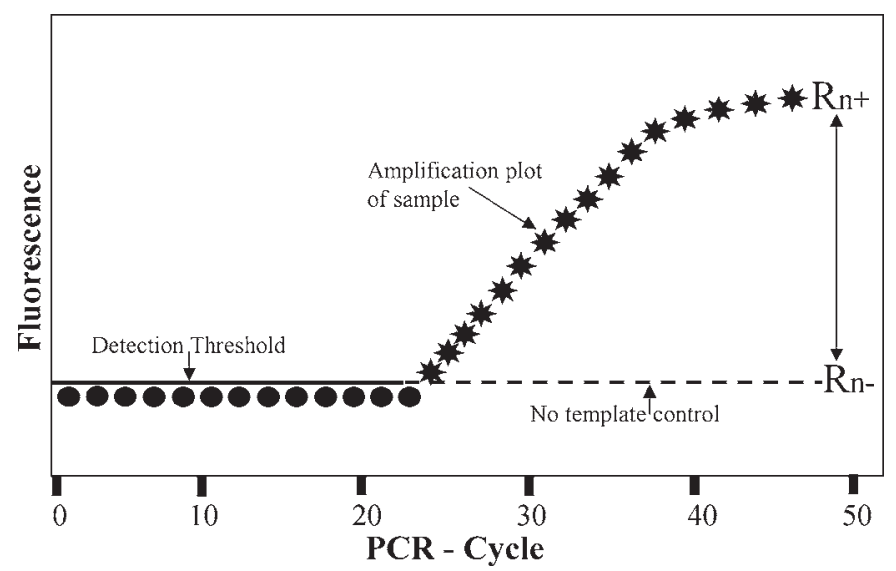

Fig. 2. Amplification plot of a singleplex assay. During the first cycles of the PCR reaction the product is below the detection threshold of the ABI PRISM. As the reaction enters the exponential phase the fluorescent signal $\left(\mathrm{R}_{\mathrm{n}}\right)$ from the newly forming PCR product is detectable. The threshold cycle (or $\mathrm{C}_{t}$ value) is the cycle at which a statistically significant increase is first detected in $R_{n}$.

cycles it takes to reach a detectable level of fluorescence $\left(\mathrm{C}_{\mathrm{t}}\right)$, the greater the initial copy number (Fig. 2).

This chapter describes how multiplex quantitative real-time PCR was used to determine the precise copy number of a candidate gene (ZNF217) from lasermicrodissected tumor material using a reference gene ( $\beta$ globin $)$ for comparison purposes. The difference between the $C_{t}$ of the control gene and the $C_{t}$ of the candidate gene varies depending on the gene copy number of the candidate gene (Eq. 1) (8). Exact gene copy number can then be calculated from the $\Delta \mathrm{C}_{\mathrm{t}}$ value.

$$
\mathrm{C}_{\mathrm{t}} \text { ZNF217 }-\mathrm{C}_{\mathrm{t}} \beta \text { globin }=\Delta \mathrm{C}_{\mathrm{t}}
$$

This approach can be used to measure the gene copy of any candidate gene for which a gene sequence is available.

\section{Materials}

1. Quantitative real-time PCR system (ABI7700 PRISM sequence detector from PE Applied Biosystems, Warrington, Cheshire, UK).

2. Laser capture microdissection system (PixCell II from Arcturus Engineering, Mountain View, CA).

3. Laser microdissection caps (CapSure ${ }^{\mathrm{TM}}$ LCM transfer film; Arcturus Engineering).

4. Primer and probe design program (Primer Express program from PE Applied Biosystems). 
5. Notepad (Microsoft, Windows Millennium Edition).

6. Gene sequence databases (http://www.ncbi.nlm.nih.gov/).

7. Oligonucleotide primers.

8. Taqman Universal PCR master mix (PE Applied Biosystems).

9. Fluorescently labeled oligonucleotide probes.

10. Proteinase K.

11. $-80^{\circ} \mathrm{C}$ Storage facility.

12. $-20^{\circ} \mathrm{C}$ Cryotome.

13. Ethanol.

14. Xylene.

15. Toluidine blue: $1 \%$ toluidine blue in $50 \%$ isopropanol.

16. Digestion buffer: $50 \mathrm{~m} M$ Tris-HCl, $1 \mathrm{~m} M$ EDTA, $0.5 \%$ Tween-20 (pH 8.5).

17. Water bath.

18. Liquid nitrogen.

\section{Methods}

The methods described below outline (1) the preparation of snap-frozen tumorous material for laser microdissection, (2) laser microdissection and DNA extraction, (3) design of primer and probe from gene sequence using specific parameters for quantitative real-time PCR, (4) quantitative real-time PCR, and (5) calculation of gene copy number using $C_{t}$ values generated from quantitative real-time PCR.

\subsection{Preparation of Snap-Frozen Colon Tumor Material}

This section describes the steps involved in preparing the selected samples for laser microdissection.

1. Take the selected tissue samples from $-80^{\circ} \mathrm{C}$ storage and transport in liquid nitrogen to a suitable cutting area containing a $-20^{\circ} \mathrm{C}$ cryotome.

2. Using the cryotome cut six sections $10 \mu \mathrm{m}$ in thickness per case and adhere this tissue to glass microscope slides (three sections per slide).

3. Allow each slide to briefly air-dry at room temperature.

4. Fix each slide by placing it in $70 \%$ ethanol for $1 \mathrm{~min}$ at room temperature.

5. Stain each section in toluidine blue using a rapid staining method (9) (see Note 1). Staining with toluidine blue is performed by immersing the sections in $0.25 \%$ toluidine blue ( $\mathrm{pH} 4.5$ ) for $5 \mathrm{~s}$ at room temperature, washing briefly in $100 \%$ ethanol, and then dehydrating the sections sequentially in $100 \%$ ethanol and xylene.

6. Allow the xylene to evaporate completely from each slide and then perform laser microdissection.

\subsection{Laser Microdissection and DNA Extraction}

The next steps in this process involve isolation (in this case, of tumor cells) and DNA retrieval from the cells of interest within the specimen using laser microdissection and protease digestion, respectively. 


\subsubsection{Laser Microdissection of Tumor Material From Surrounding Normal Cells}

Tumor microdissection was performed using a PixCell II laser capture microdissection system. The laser capture system was equipped with PixCell II image archiving software. Laser settings were as follows: spot diameter set at $15 \mu \mathrm{m}$, pulse duration $5 \mathrm{~ms}$ and power $100 \mathrm{~mW}$. Tumor tissue was identified and removed by the laser to a microdissection cap. Approximately 500 laser pulses were taken per cap per tumor. One cap was used for each case.

1. Place the section for laser microdissection on the microscope stage.

2. Identify regions of the tumor within the tissue section.

3. Move the laser site over the region selected for microdissection and activate the laser.

4. After 500 laser pulses remove the microdissection cap from the section and place on a labeled microfuge tube containing $140 \mu \mathrm{L}$ of digestion buffer.

\subsubsection{DNA Extraction}

1. Add $3.5 \mu \mathrm{L}$ of $20 \mathrm{mg} / \mathrm{mL}$ proteinase $\mathrm{K}$ to each microfuge tube and incubate in a water bath overnight at $37^{\circ} \mathrm{C}$.

2. The following day, stop the digestion by placing the microfuge tube in a preheated thermal block for $10 \mathrm{~min}$ at $90^{\circ} \mathrm{C}$.

3. Store the samples at $4^{\circ} \mathrm{C}$ until required.

\subsection{Design of Primer and Probe From Gene Sequence}

The entire DNA sequence of the candidate gene (ZNF217 [Accession no. AF041259]) and the reference gene ( $\beta$ globin [Accession no. NG_000007.1]) were downloaded from the National Center for Biotechnology Information (http://www.ncbi.nlm.nih.gov/). Each gene sequence was copied into a Notepad file and then imported into the Primer Express program. Using Primer Express, optimum primers and probe were selected for each gene sequence based on guidelines recommended by PE Applied Biosystems (see Subheadings 3.3.1. and 3.3.2. below).

\subsubsection{Probe Design Guidelines}

1. Keep the G-C content in the $20-80 \%$ range.

2. Avoid runs of identical nucleotide. This is especially true for guanine, where runs of four or more Gs should be avoided.

3. Do not put a $\mathrm{G}$ on the 5 ' end.

4. Select the strand that gives the probe a greater number of Cs than Gs.

5. Using Primer Express software, the melting point $\left(\mathrm{T}_{\mathrm{m}}\right)$ should be $68-70^{\circ} \mathrm{C}$.

\subsubsection{Primer Design Guidelines}

1. Choose the primers after the probe. 
2. Design the primers as close as possible to the probe without overlapping the probe.

3. Keep the G-C content in $20-80 \%$ range.

4. Avoid runs of identical nucleotide. This is especially true for guanine, where runs of four or more Gs should be avoided.

5. Using the Primer Express software, the $\mathrm{T}_{\mathrm{m}}$ should be $58-60^{\circ} \mathrm{C}$.

6. The five nucleotides at the 3 ' end should have no more than two $\mathrm{G}$ and/or $\mathrm{C}$ bases.

Following the guidelines in Subheadings 3.3.1. and 3.3.2. the primer and probe sequences were made as follows (in all cases, the first sequence is the forward PCR primer, the second one is the Taqman probe, and the third sequence is the reverse PCR primer): (1) ZNF217, 5'-GAG GCG AGG AAG AAG GTG C, 6FAM5'-CCC ATC TGA GAT GCT CAA AGT TGC GA3'TAMRA, 5'-CGG AAG CTG GCA GCA TTT T' and (2) $\beta$ globin, 5'-CAA GAA AGT GCT CGG TGC CT, 6FAM5'-GTC CAG GTG AGC CAG GCC ATC ACT A-3'VIC, 5'-GCA AAG GTG CCC TTG AGG T.

In multiplex quantitative real-time PCR two different fluorogenic probes are used to allow each gene to be detected separately by the ABI PRISM as they are co-amplified. In this case the candidate gene probe was VIC-labeled while the reference gene was labeled with a FAM.

\subsection{Quantitative Real-Time PCR}

Before quantitative PCR can be performed it is necessary to optimize the primer and probe concentrations for use in the assay. Applied Biosystems' guidelines for primer (Subheading 3.4.1.) and probe (Subheading 3.4.2.) optimization are as follows.

\subsubsection{Determining Optimum Primer Concentration}

Using forward and reverse primer concentrations of $50 \mathrm{n} M, 300 \mathrm{n} M$, and $900 \mathrm{n} M$, determine the minimum primer concentrations giving the maximum $\Delta \mathrm{R}_{\mathrm{n}}$ (Fig. 2). This is achieved by making several master-mix (MM) reactions where the forward and reverse primers concentrations of primer are varied. The fluorogenic probe designed to complement the forward and reverse primers should be included in the reaction (to allow detection of the PCR product) at a constant concentration (e.g., $50 \mathrm{n} M$ ) of all reactions. In all, $9 \mathrm{MM}$ reactions are prepared, each containing different concentrations of forward and reverse primers as follows:

1. $50 \mathrm{n} M$ forward primer and $50 \mathrm{n} M$ reverse primer (for plate wells A1-A4).

2. $50 \mathrm{n} M$ forward primer and $300 \mathrm{n} M$ reverse primer (for plate wells A5-A8).

3. $50 \mathrm{n} M$ forward primer and $900 \mathrm{n} M$ reverse primer (for plate wells A9-A12).

4. $300 \mathrm{n} M$ forward primer and $50 \mathrm{n} M$ reverse primer (for plate wells B1-B4).

5. $300 \mathrm{n} M$ forward primer and $300 \mathrm{n} M$ reverse primer (for plate wells B5-B8). 
6. $300 \mathrm{n} M$ forward primer and $900 \mathrm{n} M$ reverse primer (for plate wells B9-B12).

7. $900 \mathrm{n} M$ forward primer and $50 \mathrm{n} M$ reverse primer (for plate wells $C 1-\mathrm{C} 4$ ).

8. $900 \mathrm{n} M$ forward primer and $300 \mathrm{n} M$ reverse primer (for plate wells C5-C8).

9. $900 \mathrm{n} M$ forward primer and $900 \mathrm{n} M$ reverse primer (for plate wells C9-C12).

Enough of each MM should be prepared for a quadruplicate reaction (see Note 2). Each well is a $50-\mu \mathrm{L}$ reaction (i.e., $4 \times 50 \mu \mathrm{L}=200 \mu \mathrm{L}$ of each $\mathrm{MM}$ is required) (see Note 3 ).

\subsubsection{Determining Optimum Probe Concentration}

Following primer optimization, probe optimization should be initiated. To determine which probe concentration gives the maximum $\Delta \mathrm{R}_{\mathrm{n}}$, run four replicates at $50 \mathrm{n} M$ intervals from 50-250 $\mathrm{n} M$ with the previously selected optimum primer concentrations as follows:

1. Optimum primers $+0.5 \mu \mathrm{L}$ of probe (i.e., $50 \mathrm{n} M$ ) (for plate wells $\mathrm{A} 1-\mathrm{A} 4$ ).

2. Optimum primers $+1.0 \mu \mathrm{L}$ of probe (i.e., $100 \mathrm{n} M$ ) (for plate wells A5-A8).

3. Optimum primers $+1.5 \mu \mathrm{L}$ of probe (i.e., $150 \mathrm{n} M$ ) (for plate wells A9-A12).

4. Optimum primers $+2.0 \mu \mathrm{L}$ of probe (i.e., $200 \mathrm{nM}$ ) (for plate wells B1-B4).

5. Optimum primers $+2.5 \mu \mathrm{L}$ of probe (i.e., $250 \mathrm{nM}$ ) (for plate wells B5-B8).

Enough of each MM should be prepared for a quadruplicate reaction. Each well is a $50-\mu \mathrm{L}$ reaction (i.e., $4 \times 50 \mu \mathrm{L}=200 \mu \mathrm{L}$ of each $\mathrm{MM}$ is required).

Optimum conditions in this assay were: $300 \mathrm{n} M$ forward primer, $50 \mathrm{n} M$ reverse primer, and $100 \mathrm{n} M$ of probe for $\beta$ globin, and $50 \mathrm{n} M$ forward primer, $300 \mathrm{n} M$ reverse primer, and $100 \mathrm{n} M$ of probe for ZNF217 (see Notes 4-6). Quantitative real-time PCR was performed using a 50- $\mu \mathrm{L}$ final reaction volume containing $2 \mu \mathrm{L}$ volume of microdissected/proteinase $\mathrm{K}$ digested supernatant for each sample with $48 \mu \mathrm{L}$ of Taqman Universal PCR master mix containing the optimized primer and probe concentrations for multiplex realtime PCR of $\beta$ globin and ZNF217. The PCR conditions used in all reactions were: $2 \mathrm{~min}$ at $50^{\circ} \mathrm{C}, 10 \mathrm{~min}$ at $95^{\circ} \mathrm{C}$ with 40 two-step cycles of $95^{\circ} \mathrm{C}$ at $15 \mathrm{~s}$ and $60^{\circ} \mathrm{C}$ at $60 \mathrm{~s}$.

\subsection{Calculation of Gene Copy Number Using $C_{t}$ Values}

The amount of information one gets out from the assay depends on whether there is another source of data regarding the cell samples.

Subheading 3.5.1. describes a situation in which gene amplification is determined relative to a sample know to be diploid for the candidate gene. This approach allows gene amplification to be detected and relative gene amplification between the different cases to be calculated but it cannot produce a precise copy number for the candidate gene in one sample. Specific gene copy num- 


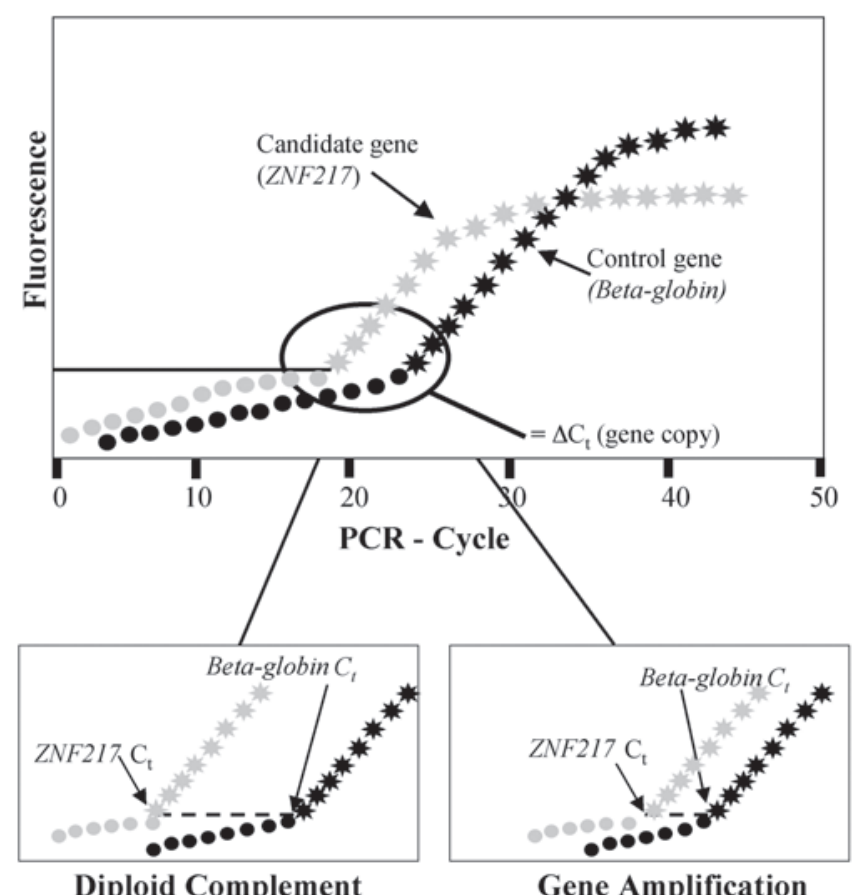

Fig. 3. Amplification plots observed in a multiplex real-time PCR. The position of the ZNF217 amplification plot (and hence its $\mathrm{C}_{\mathrm{t}}$ ) will shift relative to the internal control ( $\beta$ globin $)$ depending on the gene copy at this locus. The greater the shift to the right the greater the increase in gene copy and vice versa.

bers can be calculated only if a small proportion of the samples under investigation have been independently assigned a copy number by other methods, e.g., fluorescence in situ hybridization (FISH) analysis.

Subheading 3.5.2. describes an experiment in which FISH analysis of eight colorectal cell lines allowed the rapid and accurate assignment of a candidate gene (ZNF217) to 80 colon tumors.

\subsubsection{Detection of Gene Amplification Relative to Known Diploid Samples}

The difference between the $\mathrm{C}_{\mathrm{t}}$ of the control gene and the $\mathrm{C}_{\mathrm{t}}$ of the candidate gene varies depending on the gene copy number of the candidate gene (Eq. 1). By including known diploid samples in the assay it is possible to determine a $\Delta \mathrm{C}_{\mathrm{t}}$ value for which amplification of the candidate gene has occurred relative to the samples diploid for the candidate (Fig. 3) (see Note 7). 


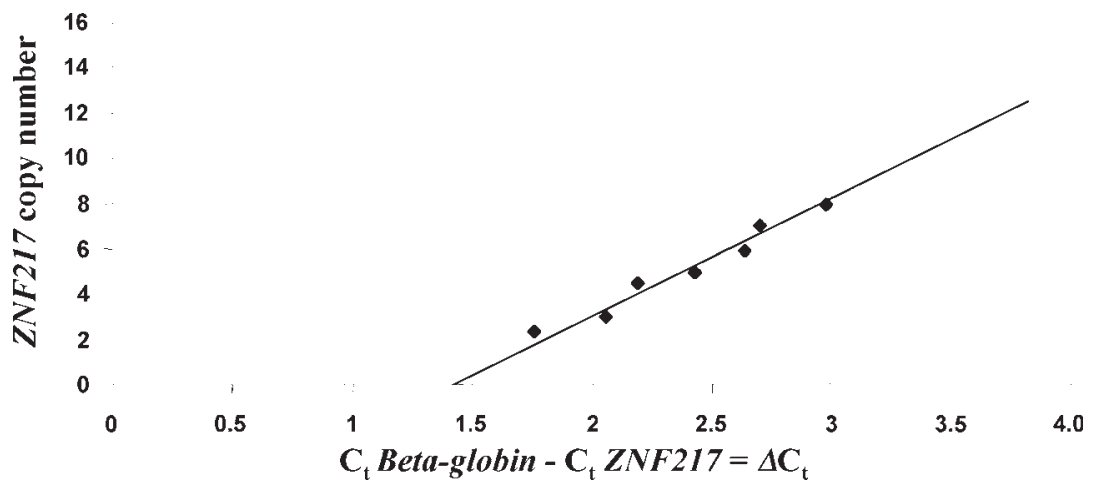

Fig. 4. A representative plot of $\Delta \mathrm{C}_{\mathrm{t}}$ determined by real-time PCR against ZNF217 gene copy number calculated by FISH.

\subsubsection{Calculation of Precise Gene Copy Using Cell Lines With Known Candidate Gene Amplification}

Using cell lines for which the ZNF217 gene copy number was known, as assessed by FISH (Fig. 4), it was possible to assign a gene copy number to the values of $\mathrm{C}_{\mathrm{t}}$ ZNF217 minus $\mathrm{C}_{\mathrm{t}} \beta$ globin (i.e., $\Delta \mathrm{C}_{\mathrm{t}}$ ) generated for those same cell lines when assessed by quantitative real-time PCR. Real-time PCR of the $\beta$ globin and ZNF217 loci in colorectal cell lines for which the ZNF217 gene copy had been independently established by FISH allowed the conversion of $\Delta \mathrm{C}_{\mathrm{t}}$ values to ZNF217 gene copy number (see Note 7). Extrapolation of the line of "best fit" is required to calculate the ZNF217 copy number in specimens with more than eight copies (the maximum amplification detected by FISH in the colorectal cell lines).

\section{Notes}

1. In this study, snap-frozen tissue was laser microdissected (Subheading 3.1.). A similar method can be used to laser microdissect paraffin-embedded material but it is recommended that hematoxylin stain be used in place of toluidine blue. The laser removes hematoxylin material more effectively than toluidine blue-stained wax sections. For snap-frozen tissue both stains are suitable.

2. Primer and probe concentration optimization should be performed in quadruplicate. However, when performing the assay on specimen DNA we have determined that performing the assay in triplicate is sufficient. This has three benefits: it reduces the amount of DNA required, it allows more samples to run in every 96-well plate, and it also reduces the cost by reducing the amount of reagents required per sample assessed.

3. The use of a digital pipet is recommended. Our laboratory has shown that a Finnipipette produces less variation between triplicates than, e.g., a manual 
Gilson pipet. To determine if accurate pipetting is being performed the variation of the triplicate mean $C_{t}$ should be calculated for each well. Only sample $C_{t}$ values lying within $10 \%$ of the mean should be accepted.

4. One internal control used in multiplex PCR is better than two external controls in a singleplex assay. We have tested both methods and determined that any benefit incurred by the inclusion of two reference genes is removed when it is realized that it is not possible to add exactly the same amount of starting template to each well (see Note 3). If precisely the same volume of template is not added in wells containing the primers amplifying the candidate gene and the reference gene the $\mathrm{C}_{\mathrm{t}} \mathrm{s}$ generated from such a analysis are not comparable. By using a multiplex system it is ensured that the same amount of template is available to the reference gene as the candidate gene, because they both are amplified in the same well. In addition the multiplex method allows more samples to be assessed per 96-well plate and subsequently is more cost-effective.

5. It is recognized that for the vast majority of Taqman assays using a concentration of $900 \mathrm{n} M$ primers and a $250 \mathrm{n} M$ probe provides for a highly reproducible and sensitive assay when using cDNA or DNA as a substrate in a singleplex assay. This is not the case when using multiplex PCR and consideration must be given to the final primer concentration selected so that it encourages "primer starvation." Primer starvation is a term used to describe a deliberate reduction in the concentration of primers of the fastest amplifying gene in a multiplex reaction. In multiplex quantitative real-time PCR it is designed to stop the amplification of the fastest amplifying product after its $\mathrm{C}_{\mathrm{t}}$ has been attained, allowing optimum amplification of the second PCR product in a master-mix "rich" environment. Without primer starvation the fastest amplifying gene product will "steal" the master mix before the second gene has reached its $\mathrm{C}_{\mathrm{t}}$.

6. Investigators are encouraged to optimize primer and probe concentrations as described but maintain default PCR cycle conditions $\left(2 \mathrm{~min}\right.$ at $50^{\circ} \mathrm{C}, 10 \mathrm{~min}$ at $95^{\circ} \mathrm{C}$, with 40 two-step cycles of $\left[95^{\circ} \mathrm{C}\right.$ at $15 \mathrm{~s}$ and $60^{\circ} \mathrm{C}$ at $\left.\left.60 \mathrm{~s}\right]\right)$.

7. A set of known standards should be included in every 96-well plate. Known standards are cases that have been assessed by other methods at the locus of interest. Ideally the known standards will have variable gene copy numbers (see Subheading 3.5.2.). If such specimens are not available, known diploid cases will suffice (see Subheading 3.5.1.). In either case these standards will allow any interplate variability to be detected.

\section{Acknowledgment}

The author would like to thank Dr. M. C. E. McFadyen for helpful discussion and technical assistance with the described assay.

\section{References}

1 Copur, S., Aiba, K., Drake, J. C., Allegra, C. J., and Chu, E. (1995) Thymidylate synthase gene amplification in human colon cancer cell lines resistant to 5-fluorouracil. Biochem. Pharmacol. 49, 1419-1426. 
2 Boonsong, A., Marsh, S., Rooney, P. H., Stevenson, D. A. J., Cassidy, J., and McLeod H. L. (2000) Characterization of topisomerase I locus in human colorectal cancer. Cancer Genet. Cytogenet. 121, 56-60.

3 Curran, S., McKay, J. A., McLeod, H. L., Murray, G. I. (2000) Laser capture microscopy. J. Clin. Pathol.: Mol. Pathol. 53, 64-68

4 Higuchi, R., Dollinger, G., Walsh, P. S., and Griffith, R. (1992) Simultaneous amplification and detection of specific DNA sequences. BioTechnol. 10, 413-417.

5 Higuchi, R., Fockler, C., Dollinger, G., and Watson, R. (1993) Kinetic PCR analysis: Real-time monitoring of DNA amplification reactions. BioTechnol. 11, $1026-1030$.

6 Holland, P. M., Abramson, R. D., Watson, R., and Gelfand, D. H. (1991) Detection of specific polymerase chain reaction product by utilizng the $5^{\prime}$ to $3^{\prime}$ exonuclease activity of Thermus aquaticus DNA polymerase. Proc. Natl. Acad. Sci. USA 88, 7276-7280.

7 Livak, K. J., Flood, S. J. A., Marmaro, J., Giusti, W., and Dertz, K. (1995) Oligonucleotides with fluorescent dyes at opposite ends provide a quenched probe system useful for detecting PCR product and nucleic acid hybridization. PCR Methods and Applications 4, 357-362.

8. Glöckner, S., Lehmann, U., Wilke, N., Kleeberger, W., Länger, F., and Kreipe, H. (2000) Detection of gene amplification in intraductal and infiltrating breast cancer by laser-assisted microdissection and quantitative real-time PCR. Pathobiol. 68, 173-179.

9. Lawrie, L. C., Curran, S., McLeod, H. L., Fothergill, J. E., and Murray, G. I. (2001) Applications of laser capture microdissection and proteomics in colon cancer. J. Clin. Pathol.: Mol. Pathol. 54, 253-258. 